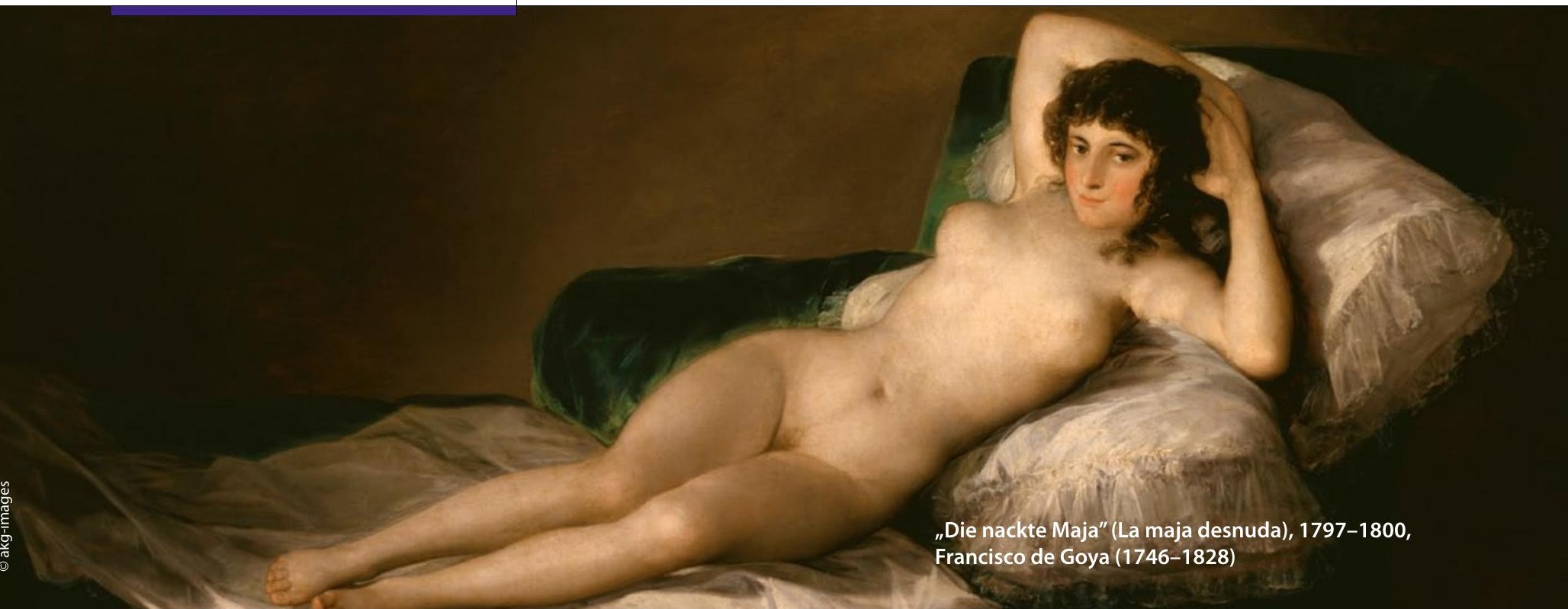

\title{
Francisco de Goya
}

\section{Skandal der Sinnlichkeit}

\author{
Es ist das Skandalbild der spanischen Kunstgeschichte schlechthin. Gleichzeitig wohl das berühmteste Werk \\ des wohl größten Malers des Landes. „Die nackte Maja“ führte dazu, dass Francisco de Goya 1815 vor die \\ Spanische Inquisition zitiert wurde um herauszufinden, wer ihn beauftragt habe, dieses „obszöne“ Bild zu \\ malen. Als Folge des Prozesses wurde dem bis dahin hoch geehrten Künstler der Titel des Königlichen \\ Hofmalers aberkannt.
}

W as war nun eigentlich so skandalös an dem Bild? Nackte Frauenkörper in der Kunstgeschichte hatte es doch schon immer gegeben. Kaum ein großer Maler, der sich nicht in der Aktmalerei versucht hatte. War es die Tatsache, dass Goya hier erstmals einen Hauch von Schambehaarung mitmalte, was nach Angaben des Kunsthistorikers Robert Hughes zum ersten Mal in der abendländischen Kunst geschah?

Das mag schamhaargenau beobachtet sein, dennoch war es wohl eher etwas anderes, das Anstoß erregte. Maler, die sich in der Generation vor Goya dem weiblichen Körper widmeten, siedelten diesen zumeist im Bereich der Mythologie oder Allegorie an. Wenn Velasquez eine nackte Venus schuf, die sich selbstverliebt im Spiegel betrachtete, so war dies kein Problem. Auch Dürers Eva ist bis auf ein winziges Feigenblatt völlig unbekleidet. Und Rubens malte während seines langen Künstlerlebens ganze Tonnen nackten weiblichen Fleisches, wofür ihm die Mythologie des Abendlandes reichlich Material lieferte.

Goya aber macht etwas anderes. Er malt keine griechische Göttin, keine Allegorie der Frauenschönheit, sondern einfach eine echte nackte Frau. Eine, die es zu seiner Zeit wirklich gab. Und sie schämt sich ihrer Nacktheit in keiner Weise. Erotisch, selbstbewusst und einladend liegt sie da - ohne Schmuck, ohne Zierrat und mit einem leicht amüsierten Lächeln. Ein Vollblutweib.

„Maja“ ist dabei weniger ein Name als ein Gattungsbegriff. Als Maja wurden in Madrid jene frechen, freilebigen, aber auch stolzen Frauen der Unterschicht bezeichnet, die den Urtypus spa- nischer Lebensart verkörperten. Bei den Damen der Oberschicht galt es durchaus als schick, sich gelegentlich im „Majakostüm“ zu präsentieren.

Und der Oberschicht entstammte wohl auch das tatsächliche Modell für Goyas berühmtes Werk. Unter Kunsthistorikern gilt es als weitgehend gesichert, dass es sich bei der Dargestellten um die Herzogin von Alba handelt, die Goya zuvor bereits mehrfach - allerdings bekleidet - porträtiert hatte und zu der er offensichtlich eine Liebesbeziehung unterhielt.

Ihren Zeitgenossen galt die Herzogin als außergewöhnlich extrovertiert und freizügig. Das hat wohl nicht zuletzt mit ihrer Kindheit und Jugend zu tun. Früh verwaist, wurde sie von ihrem Großvater erzogen, der ein glühender Verehrer des französischen Aufklärungsphilosophen Jean Jacques Rousseau war. „Frei und wild sollte sie aufwachsen, ohne jedweden Zwängen gehorchen zu müssen, so dass sich ihre geistigen und körperlichen Fähigkeiten frei entwickeln könnten, denn das Natürliche und Gefühlsbetonte im Menschen darf durch die Anpassung an die Gesellschaft nicht verdorben werden“. So lauten die wichtigsten Forderungen Rousseaus für die Erziehung von Kindern, die er in seinem pädagogischen Roman „Emile“ publiziert hatte. Dieser erschien im Geburtsjahr der jungen Herzogin.

Es sieht ganz so aus, als ob die Herzogin ihren Großvater mit ihrem Charakter nicht enttäuscht hat. Mit ihrem nackten Körper hat sie auf jeden Fall Kunstgeschichte geschrieben.

Prof. Dr. med. B. Kleine-Gunk 